\title{
Factors Associated with Treatment Adherence of Brazilian Patients Undergoing Hemodialysis
}

\author{
Factores asociados con la adherencia al tratamiento \\ de pacientes brasileños en hemodiálisis
}

\author{
Renata Tamie Nakao ${ }^{1}$ \\ Ricardo Gorayeb ${ }^{2}$ \\ José Abrão Cardeal da Costa ${ }^{3}$ \\ Ribeirão Preto Medical School, University of São Paulo, Brazil
}

\begin{abstract}
To evaluate patients' adherence to hemodialysis (HD) and its relationship to psychosocial variables. Methods: 64 adult patients undergoing HD participated in the study and were assessed in regard to depression, anxiety, social support, disease and treatment knowledge, and adherence. Results: Association between sex and adherence to HD, and to diet and medication was found, as well as between schooling and overall adherence. There is association between disease knowledge and depression, with adherence to fluid restrictions. No association was found between adherence and anxiety. Conclusion: Identifying the determinants of treatment adherence is essential to devise efficacious strategies to improve patients' quality of life.
\end{abstract}

Keywords. Hemodialysis, depression, anxiety, social support, treatment adherence.

Resumen. Objetivo: Evaluar la adherencia de pacientes al tratamiento de la hemodiálisis (HD) y su relación con variables psicosociales. Método: Participaron 64 pacientes adultos con HD, evaluados en cuanto a depresión, ansiedad, apoyo social, conocimiento de la enfermedad y del tratamiento, y la adherencia. Resultados: Hay asociación entre sexo y adherencia a la HD, la dieta y la medicación, así como entre escolaridad y la adherencia general. Hay asociación entre niveles de conocimiento de la enfermedad y depresión con la adherencia a la restricción de líquidos. No se encontró asociación entre la adherencia y la ansiedad. Conclusión: La identificación de los determinantes de la adherencia al tratamiento es esencial para la elaboración de estrategias eficaces para mejorar la calidad de vida de los pacientes.

Palabras clave. Hemodiálisis, depresión, ansiedad, apoyo social, adherencia.

\footnotetext{
${ }^{1}$ Renata Tamie Nakao. Department of Neurosciences and Behavioral Sciences, Ribeirão Preto Medical School, University of São Paulo. Brazil. Postal Address: Av. Bandeirantes, 3900. Monte Alegre. Postal Code: 14049-900. Ribeirão Preto, São Paulo, Brazil. E-mail: renatanakao@usp.br

${ }^{2}$ Ricardo Gorayeb. Department of Neurosciences and Behavioral Sciences, Ribeirão Preto Medical School, University of São Paulo. Brazil. E-mail: rgorayeb@fmrp.usp.br

${ }^{3}$ José Abrão Cardeal da Costa. Department of Internal Medicine, Ribeirão Preto Medical School, University of São Paulo. E-mail: jacdcost@fmrp.usp.br
}

\section{@ $\Theta \Theta \Theta$}

Esta obra está bajo una licencia de Creative Commons Reconocimiento-NoComercial-SinObraDerivada 4.0 Internacional. 


\section{Introduction}

Because of its high prevalence worldwide, end-stage renal disease (ESRD) became an important public health problem. In Brazil, estimates indicate that up to 1.4 million people are affected by renal failure (Romão, 2004). Hemodialysis (HD) is the main form of renal replacement therapy, used by $91.6 \%$ of Brazilian ESRD patients (Sesso, Lopes, Thomé, Lugon \& dos Santos, 2011).

Despite important technological advancements in the treatment of ESRD and increased survival of patients, none of the existing treatments is curative, that is, patients are required to deal with the chronic nature of the disease and with the limitations imposed by replacement therapies, which takes quite a toll in psychological terms. HD is associated with important losses such as loss of a feeling of well-being, sexual function, job, leisure, and also loss of time, sense of being useful and autonomy (Zimmerman, Carvalho \& Mari, 2004; Martins \& Cesarino, 2005). Food and fluid restrictions aggravate the treatment's restrictive nature and force individuals to adapt to a new lifestyle (Madeiro, Machado, Bonfim, Braqueais \& Lima, 2010).

Depressive manifestations are expected in the initial period of treatment and such manifestations may function as an adaptive response in the face of insecurity and losses (Zimmerman et al., 2004). When, however, depressive manifestations take longer than the period of adaptation, they may develop into a depressive condition, the psychological disorder more frequently investigated among patients undergoing HD.

Brazilian and international studies report high levels of depression, ranging from $25 \%$ to more than $60 \%$ of the studied samples (Nifa \& Rudnicki, 2010; Khalil, Frazier, Lennie \& Sawaya, 2011; Turkmen et al., 2012; Ossareh, Tabrizian, Zebarjadi \& Joodat, 2014).

Other psychological disorders are observed in HD patients and anxiety is a very important one. Despite its importance, data concerning its occurrence and impact on the life and treatment of these individuals are still scarce. Anxiety disorders are usually considered part of depressive disorders rather than being treated as independent conditions (Cukor et al., 2008).

The level of perceived social support also seems to influence the physical and emotional health of individuals with chronic diseases. There is empirical evidence that one's perception of available social support positively contributes to the functioning and well-being of individuals, and for this reason, this variable has been studied in the health field.

\section{Adherence to bemodialysis}

Much of the therapeutic success achieved by patients undergoing HD depends on treatment adherence; however, the literature suggests that between $30 \%$ and $50 \%$ of ESRD patients do not adhere to HD, a situation that may be associated to medical complications, as well as low rates of survival (Rosenthal-Asher, Ver-Halen \& Cukor, 2012; Clark, Farrington \& Chilcot, 2014).

Numerous studies seek potential explanations for and determinants of adherence to HD, but the variety of tools and parameters used hinder comparison and generalization of data. The self-reporting of patients, assessment scales, structured interviews, as well as objective measures such as assessment of phosphorus levels in the blood or interdialytic weight gain have been used (Clark et al., 2014; Schmid, Hartmann \& Schiffl, 2009). No consensus, however, has been reached in regard to the establishment of a cut-off point for these indicators (Kugler, Vlaminck, Haverich \& Maes, 2005).

Additionally, due to the high complexity of the treatment, most studies focus on the analysis of one of the treatment aspects (i.e., adherence to medication, or to fluid or diet restrictions), which hinders the establishment of general conclusions (Schmid et al., 2009; Martins et al., 2013; Alkatheri et al., 2014).

This study's aim was to assess adherence to different aspects of the HD treatment of ESRD patients and identify the relationship between adherence to treatment and sociodemographic and psychological variables. It is possible that low socioeconomic status, the presence of psychological disorders, poor social 
support, and a limited understanding of the disease negatively influence adherence to treatment.

\section{Methods}

This quantitative descriptive cross-sectional study included a convenience sample of ESRD patients undergoing $\mathrm{HD}$ in a public university hospital in the interior of São Paulo state, Brazil. The project was approved by the Institutional Review Board and all the participants signed informed consent forms.

Patients

Patients aged 18 years old or older, of both sexes, undergoing HD for at least six months, were included.
Institutionalized patients or those unable to understand and/or verbally answer the questions in a clear and consistent manner due to some disability or cognitive impairment were excluded.

A total of 64 patients participated in the study. The sampling process is presented in figure 1 .

The sample's sociodemographic characteristics are presented in table 1.

\section{Instruments}

A semi-structured interview script. Developed by the researchers to collect sociodemographic and clinical data, and the patient's level of knowledge concerning the

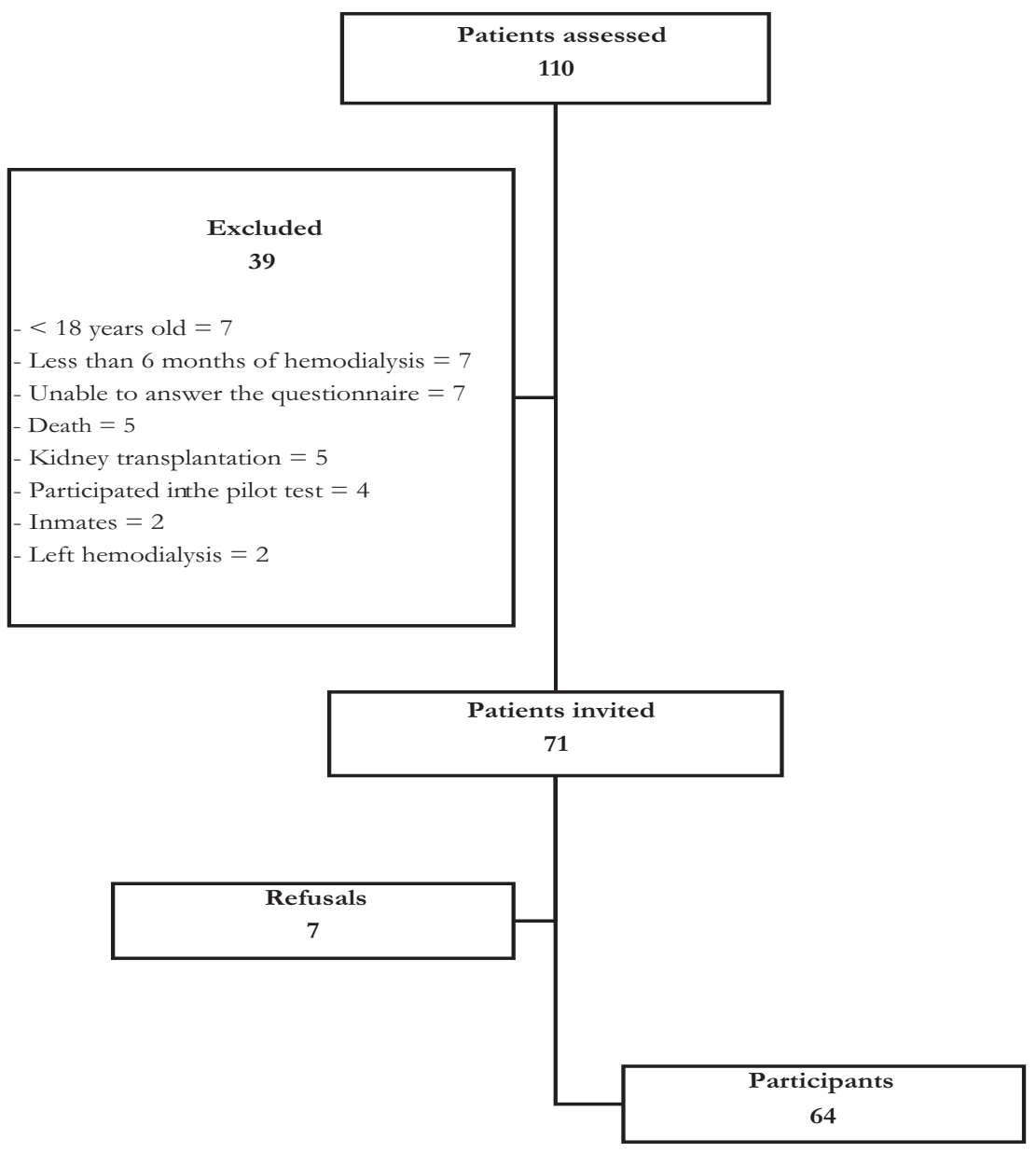

Figure 1. Sampling process of Brazilian patients undergoing hemodialysis. 
Table 1

Sociodemographic characteristics of a sample of Brazilian patients undergoing hemodialysis $(N=64)$

\begin{tabular}{llrr}
\hline Variable & & Freq. & $\%$ \\
\hline Sex & male & 33 & 51.56 \\
Age & Up to 40 years old & 18 & 28.12 \\
& From 40 to 60 years old & 31 & 48.44 \\
& Older than 60 years old & 15 & 23.44
\end{tabular}

Years of education

$\begin{array}{lll}0 \text { to } 7 & 30 & 46.87 \\ 8 \text { to } 10 & 12 & 18.75 \\ 11 \text { or more } & 22 & 34.38\end{array}$

Marital status

Has a partner

City of origin

Same city as the hospital

Up to $50 \mathrm{~km}$ away

From 50 to $100 \mathrm{~km}$ away

More than $100 \mathrm{~km}$ away

Note. MW (minimum wage) equivalent to R $\$ 222.00$ (approximately U\$311.00) at the time of data collection.

disease and treatment. The assessment of knowledge included asking patients to explain what they knew about the ESRD and which behaviors are involved in its treatment. The answers were later categorized and classified as "satisfactory" or "unsatisfactory".
The Hospital Anxiety and Depression Scale (HADs). Which assesses mild degrees of mood disorders in non-psychiatric environments and in situations of physical morbidity. In regard to the psychometric properties of the instrument's Brazilian version, 
Cronbach's alpha ranged from .68 to .84 for the anxiety subscale and from .77 to .83 for the depression subscale. In terms of criterion validity, the correlation of HADs with the Beck scales ranged from .6 to .7, which can be considered good to very good (Botega, Bio, Zomignani, Garcia \& Pereira, 1995; Marcolino et al., 2007).

The Social Support Scale. Originally developed for the Medical Outcomes Study (MOS), which comprises three dimensions of social support: (a) positive social interaction/affective support, (b) emotional/ informational support; (c) material support. The instrument's Brazilian version presents Cronbach's alpha equal to or greater than .83 in all dimensions (Griep, Chor, Faerstein \& Lopes, 2003; Griep, Chor, Faerstein, Werneck \& Lopes, 2005). There are no Brazilian studies addressing this instrument's validity.

Data were also collected from the participants' medical files, namely: number of HD sessions missed; interdialytic weight gain; and levels of phosphorus in the blood. Information concerning the three months prior to data collection was included to avoid any medical complication that could have altered the participant's clinical condition in a given month introducing bias into data interpretation.

\section{Procedure}

The patients were contacted during their HD sessions, without, however, interfering in them in any way. Due to the reading and comprehension problems of some patients, all the questions and alternative responses of the standardized instruments were read, to which the participant responded orally.

Data were collected from May to October 2012, a time when all the patients who met the inclusion criteria were invited to participate in the study.

The participants were assessed in regard to treatment adherence according to the parameters used in the unit where data were collected; the parameters are presented in table 2 .

The number of HD sessions missed was used to determine adherence to HD. Interdialytic weight gain (IDWG) was used to classify the participants in regard to adherence to fluid restrictions, while PO4 exams

Table 2

Criteria to classify participants regarding adherence to hemodialysis treatment

\begin{tabular}{|c|c|c|}
\hline & Adherent & Non-adherent \\
\hline Number of sessions missed & 0 or 1 & $>1$ \\
\hline \multirow[t]{6}{*}{ IDWG } & $\begin{array}{l}\text { I- Mean up to } 5 \% \text { of DW on the weekend } \\
\text { AND }\end{array}$ & $\begin{array}{l}\text { I- Mean greater than } 5 \% \text { of } \\
\text { DW on the weekend }\end{array}$ \\
\hline & II- up to $3 \%$ of DW during the week & OR \\
\hline & AND & II- More than $3 \%$ of DW during the week \\
\hline & III- more than $50 \%$ of & OR \\
\hline & days with appropriate & III- Less than $50 \%$ of the days \\
\hline & IDWG & with appropriate IDWG \\
\hline PO4 $(m g / d l)$ & Up to 5.5 & $>5.5$ \\
\hline Number of medical consultat & ns missed & $>1$ \\
\hline
\end{tabular}

IDWG: Interdialitc weight gain. DW: Dry weight. $\mathrm{PO}_{4}$ : Phosphorus level in blood. 
were used to check adherence to diet and medication. Finally, the number of missed medical consultations was used to establish adherence to consultations. The participants were also classified as adherent or nonadherent, in general, which was called here "Overall Adherence". To be considered "adherent" the patient had to meet the adherence criteria in all the aspects of treatment; thus, lack of adherence to one of the four aspects previously mentioned (i.e., HD, fluid restrictions, diet and medication, and consultations) was sufficient to classify a patient as "non-adherent".

\section{Statistical analysis}

The Mann-Whitney test for independent samples was used to compare some groups' numerical variables (age, distance from city of origin, monthly income and social support). In these cases, results are reported in terms of differences between adherent and nonadherent groups. Fisher's exact test was used to verify association among categorical variables (sex, schooling, marital status, religion, working conditions, disease knowledge, depression and anxiety) and adherence. For these analyses, results are presented in terms of associations. The results were obtained with SAS® 9, using the package for non-parametric tests (PROC NPAR1WAY). The level of significance $\alpha=.05$ was adopted. Only significant results are reported.

\section{Results}

The average duration of $\mathrm{HD}$ was 65.38 months $(S D$ $=71.31 ; M=43.5$ ), ranging from 7 to 330 months. Information regarding the disease underlying ESRD is

Table 3

Diseases underlying ESRD of a sample of patients undergoing hemodialysis $(N=64)$

\begin{tabular}{lcc}
\hline Primary Disease & Freq. & $\%$ \\
\hline Hypertension & 22 & 34.38 \\
Diabetes Mellitus & 18 & 28.13 \\
Chronic glomerulonephritis & 18 & 28.13 \\
Polycystic kidney & 4 & 6.25 \\
Congenital disease & 4 & 6.25 \\
Others & 9 & 14.06 \\
\hline
\end{tabular}

Table 4

Prevalence of anxiety and depressive symptoms and perceived social support in a sample of patients undergoing hemodialysis $(\mathrm{N}=64)$

\begin{tabular}{lcc}
\hline & Psychological variables & $\%$ \\
\hline & Anxiety symptoms & 25.00 \\
& Depressive symptoms & 12.50 \\
& & Mean \\
Social Support & Overall mean & 86.96 \\
& Positive social interaction/Affective & 89.20 \\
& support & 84.84 \\
& Emotional/Informational support & 87.27 \\
\hline
\end{tabular}


provided in Table 3. Diseases such as Lupus, Berger's syndrome, Focal segmental glomerulosclerosis (FSGS), nephritis, and pyelonephritis, were grouped in the category "chronic glomerulosclerosis". "Congenital diseases" included congenital malformations such as neurogenic bladder, and "Others" included diseases that presented a low frequency in this sample, such as kidney cancer and myeloma.

More than half of the sample provided a satisfactory explanation of the kidney disease (54.69\%); however, among those who provided an unsatisfactory response, $15.62 \%$ simply was unable to explain the disease, while $6.25 \%$ provided a wrong explanation. In regard to the explanation of the treatment, $57.81 \%$ provided unsatisfactory responses. In regard to psychological variables and social support, results are presented in table 4. Anxiety symptoms were observed in $25 \%$ of the sample and depressive symptoms in $12.5 \%$. The overall mean of perceived social support was 86.96, indicating good support in the sample. The dimension that obtained the highest mean was Affective Support/Positive Interaction (89.20) and the dimension with the lowest mean was Emotional/ Informational Support (84.84). The difference between the scores, however, is small and indicates that the patients' perception of social support is similarly distributed among the dimensions.

The distribution of patients in regard to treatment adherence is described in figure 2 . According to the criteria used, 44 patients $(68.7 \%)$ were found to be generally non-adherent (Overall adherence). Nonetheless, observing each aspect of the treatment separately, a prevalence of adherent patients was found, except for the Fluid Restrictions aspect, in which the number of nonadherent patients was higher $(51.6 \% ; n=33)$.

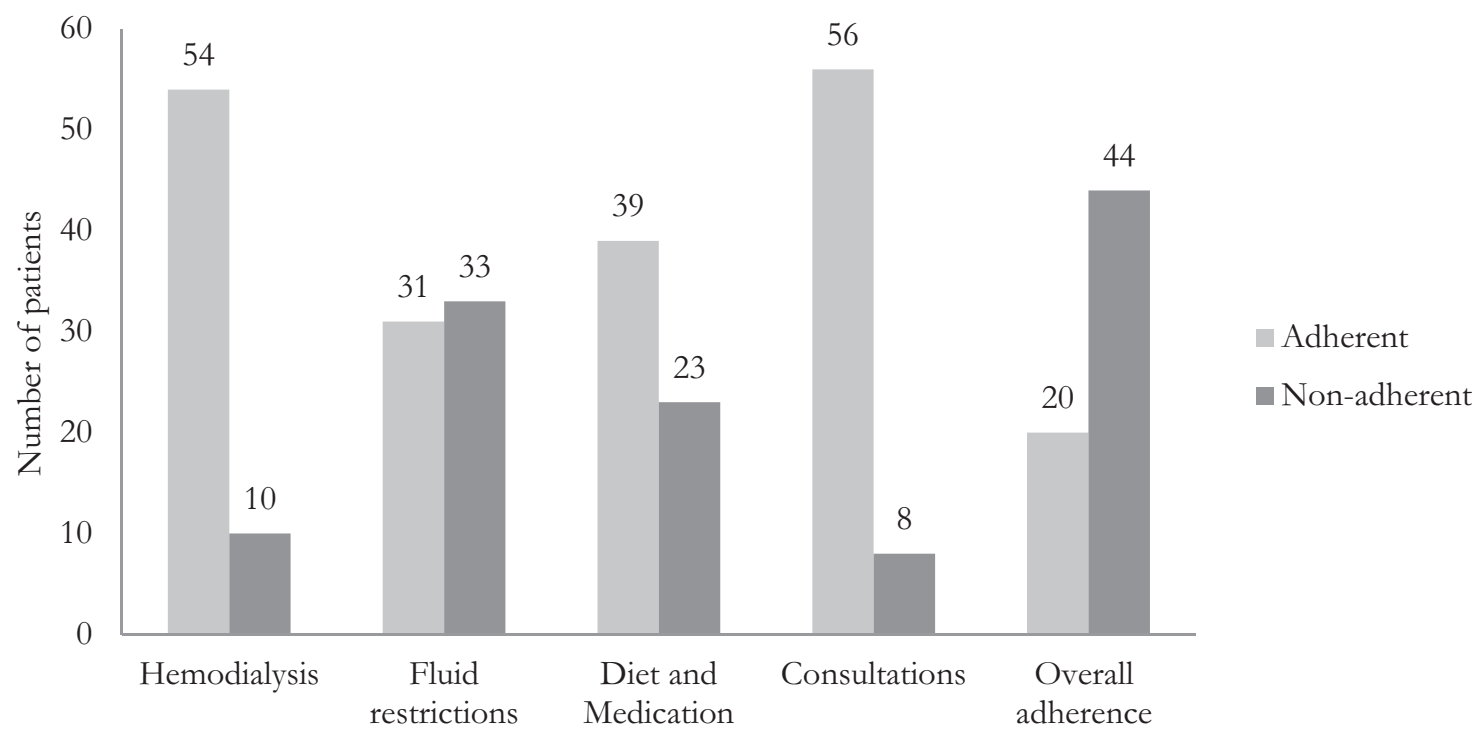

Figure 2. Adherence to the treatment's four aspects and Overall Adherence in a sample of Brazilian patients undergoing hemodialysis $(N=64)$. 
Table 5

Sociodemographic characteristics and treatment adherence in a sample of patients undergoing hemodialysis $(N=64)$

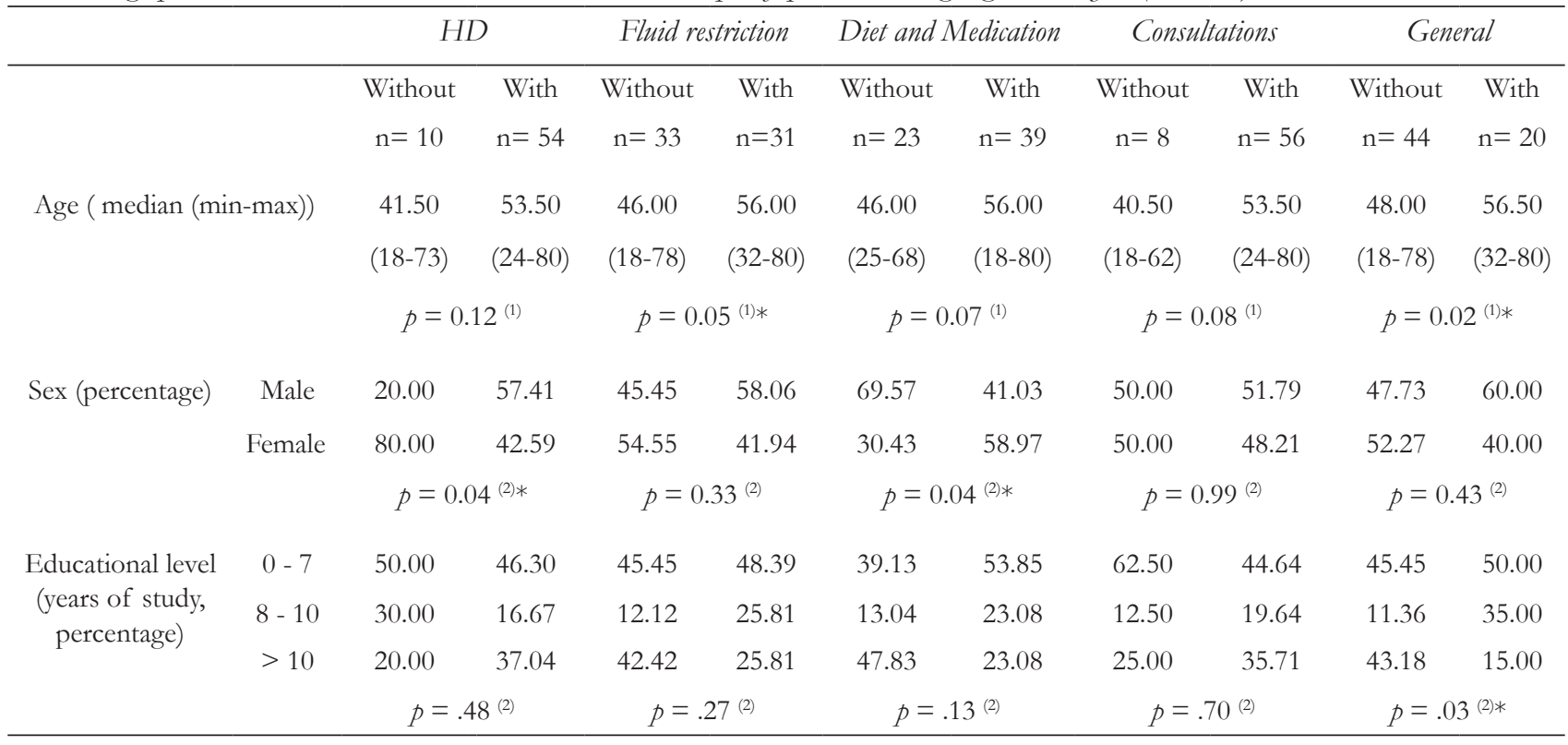

${ }^{1}$ Mann Whitney Test

${ }^{2}$ Fisher's Exact Test

$* p \leq .05$

Table 6

Psychological variables and treatment adherence in a sample of patients undergoing hemodialysis - percentages $(N=64)$

\begin{tabular}{|c|c|c|c|c|c|c|c|c|c|c|c|}
\hline & & \multicolumn{2}{|c|}{$H D$} & \multicolumn{2}{|c|}{ Fluid restriction } & \multicolumn{2}{|c|}{ Diet and Medication } & \multicolumn{2}{|c|}{ Consultations } & \multicolumn{2}{|c|}{ General } \\
\hline & & Without & With & Without & With & Without & With & Without & With & Without & With \\
\hline & & $\mathrm{n}=10$ & $\mathrm{n}=54$ & $\mathrm{n}=33$ & $\mathrm{n}=31$ & $\mathrm{n}=23$ & $\mathrm{n}=39$ & $\mathrm{n}=8$ & $\mathrm{n}=56$ & $\mathrm{n}=44$ & $\mathrm{n}=20$ \\
\hline \multirow[t]{3}{*}{ Anxiety } & Absent & 80.00 & 74.07 & 84.85 & 64.52 & 69.57 & 76.92 & 62.50 & 76.79 & 79.55 & 65.00 \\
\hline & $\begin{array}{c}n=48 \\
\text { Present }\end{array}$ & 20.00 & 25.93 & 15.15 & 35.48 & 30.43 & 23.08 & 37.50 & 23.21 & 20.45 & 35.00 \\
\hline & $n=16$ & \multicolumn{2}{|c|}{$p=0.99$} & \multicolumn{2}{|c|}{$p=0.08$} & \multicolumn{2}{|c|}{$p=0.56$} & \multicolumn{2}{|c|}{$p=0.40$} & \multicolumn{2}{|c|}{$p=0.23$} \\
\hline \multirow[t]{3}{*}{ Depression } & $\begin{array}{c}\text { Absent } \\
n=56\end{array}$ & 80.00 & 88.89 & 96.97 & 77.42 & 91.30 & 84.62 & 100 & 85.71 & 93.18 & 75.00 \\
\hline & $\begin{array}{c}\text { Present } \\
n=8\end{array}$ & 20.00 & 11.11 & 3.03 & 22.58 & 8.70 & 15.38 & 0 & 14.29 & 6.82 & 25.00 \\
\hline & & \multicolumn{2}{|c|}{$p=.60$} & \multicolumn{2}{|c|}{$p=.02 *$} & \multicolumn{2}{|c|}{$p=.70$} & \multicolumn{2}{|c|}{$p=.58$} & \multicolumn{2}{|c|}{$p=.10$} \\
\hline
\end{tabular}

Fisher's Exact Test

$* p \leq .05$ 
When the adherent and non-adherent groups were compared in terms of sociodemographic characteristics, a significant difference in regard to ages in the groups was verified concerning fluid management and the treatment as a whole, indicating that adherent patients were older than those who do not adhere to these aspects of the treatment. There was also evidence of association between sex and HD adherence. Descriptive data suggest that male patients are more likely to adhere to HD than females. Women, however, seem to be more likely to adhere to diet and medication when compared to men. In regard to education, data suggest that individuals with lower educational levels (from eight to ten years of schooling) more frequently adhere to treatment than those with more than ten years of schooling (table 5).

In regard to knowledge about the disease and treatment, association was found between explanation regarding treatment and adherence to fluid restriction $(\mathrm{p}=.01)$; the participants who provided satisfactory explanation less frequently adhered to this aspect of treatment. When associations among depression and anxiety and treatment adherence were verified, evidence of association was found between depression and adherence to fluid restrictions (table 6). Interestingly, contrary to what was hypothesized, a significantly higher percentage of patients who are non-adherent to this aspect of treatment did not present depression symptoms. In regard to perception of social support, a significant difference between groups was observed only in regard to HD adherence; i.e., the adherent patients presented higher scores of general support compared to the non-adherent group (Median 96.84 versus $81.05 ; \mathrm{p}<.05)$.

\section{Discussion}

The sociodemographic profile of this study's participants is similar to the profile of other samples of ESRD patients undergoing HD in Brazil (Sesso et al., 2011). There was a similar distribution between sexes with a slight predominance of male patients. There was a greater frequency of patients with low educational level and low income, characteristics also observed in the National Sample Survey of Households conducted by the Brazilian Institute of Geography and Statistics in 2003 concerning the sociodemographic profile of patients being cared for within the Brazilian Health System (Ribeiro, Barata, Almeida \& Silva, 2006).

In regard to the clinical characteristics, a remarkable fact was the predominance of patients who developed end-stage renal disease as a complication of controllable diseases, that is, the negative progression of which could be avoided. Studies show that poor and less-educated patients are more likely to acquire hypertension, the main underlying disease for ESRD in Brazil, as well as have poor control over the disease (Hartman, Diasda-Costa, Olinto, Patussi \& Tramontini, 2007; Carlos, Palha, Veiga \& Beccaria, 2008). These data reveal a need to implement actions to prevent ESRD directed to the risk population, which is highly prevalent in developing countries, considering the individual and social impact of the advanced stage of the disease and complex treatment it requires.

Non-adherence rates observed in this study (68.7\%) were higher than those observed in previous studies (Dantas et al., 2013; Ibrahim, Hossam \& Belal, 2015). This difference may be related to the criteria adopted in this study to classify adherence, more rigorous than those frequently adopted in studies conducted in other treatment centers. This divergence reveals a problem previously discussed concerning the absence of standardized parameters to enable conclusions and comparisons among the results of studies addressing adherence of patients to HD (Kugler et al., 2005). Thus, validation of criteria to be used in diverse samples of patients is needed to enable comparisons.

\section{Factors related to hemodialysis adherence}

Level of knowledge regarding the disease and treatment. Significant association was observed between explanation of the treatment and adherence to fluid restrictions: those who provided a satisfactory explanation of the treatment less frequently adhere to fluid restrictions. This issue is controversial in the literature. On the one hand, there are data suggesting that increased knowledge concerning the disease 
contributes to better fluid management (Thomas et al., 2001; Stamatakis, Pecora \& Gunel, 1997), while some studies report that patients with greater knowledge present poorer adherence to medical prescriptions (Durose, Holdsworth, Watson \& Przygrodzka, 2004; Nerbass et al., 2010). Note that even though treatment adherence depends on knowledge patients have concerning the disease, knowledge by itself is not a predictor of adherence. The reason is that adherence is composed of a set of different behaviors, not always inter-related, and because it is a complex construct with sophisticated functioning, it requires further research and extensive analysis.

\section{Demographic characteristics}

The average age was higher among the group that adhered to fluid restrictions and the treatment as a whole. This same association was observed in other studies addressing adherence to different aspects of the treatment (Alkatheri et al., 2014; Dantas et al., 2013; Sgnaolin, Prado \& Figueiredo, 2012).

A potential explanation for this association is that elderly people have a greater concern with death and thus comply with their treatment to avoid it. Another explanation provided by some authors is that older individuals have a more organized and structured life, a context in which they can accommodate the demands of a therapeutic regimen (Sgnaolin et al., 2012). Additionally, testing the limits of one's own body by adopting behaviors that diverge from professional orientation may be common among younger patients (Kugler et al., 2005).

In regard to sex, data suggest that male patients more frequently adhere to HD than female patients, while women more frequently adhere to diet and medication when compared to men. These results contradict the findings of Wileman et al. (2011), who assessed adherence of ESRD patients to the use of chelating phosphorus and women were five times more likely not to adhere to the medication than men. We did not find Brazilian studies addressing this association, however, we should keep in mind there is a cultural aspect in Brazil in which different social roles are established for men and women, which reflect the way these two groups deal with issues concerning health and disease (Figueiredo \& Schraiber, 2011; Knauth, Couto \& Figueiredo, 2012).

\section{Psychological variables}

The statistical analysis concerning associations between anxiety and adherence to treatment and between depression and adherence to treatment revealed few significant associations. When the association was found, it was inverse to that predicted by the hypothesis; i.e., association between depression and adherence to fluid restrictions indicated that a significant higher percentage of the non-adherent group did not present depression symptoms.

These results contradict reports in the literature that suggest there is an inverse relationship between depression and anxiety symptoms and treatment adherence (Ossareh et al., 2014; Ibrahim et al., 2015; Cé, Kamile, Ceza \& Filla, 2008; Khalil \& Frazier, 2010; Nabolsi, Wardman \& Al-Halabi, 2015).

The analysis performed does not allow for the establishment of a relationship of cause and effect between the psychological variables and treatment adherence, that is, whether the presence of depression would be the cause or consequence of adherence to treatment. It is possible that the association found is related to the restrictive nature of the hemodialysis treatment, which involves intense deprivation of primary reinforces such as fluid restrictions. In other words, deprivations imposed by the treatment may have led to the onset of depressive symptoms. Additionally, the small number of patients in the groups with anxiety and depression (16 and 8, respectively) may also explain this difference, which may have influenced the results of tests.

Some particularities concerning the study setting should be considered: this dialysis center has an interdisciplinary staff composed of physicians, nurses, nutritionists, psychologists and social workers. The objective is to integrally meet the needs of patients, including emotional needs, and reduce the aversive nature of the hospital environment by promoting 
occupational and fun tasks, commemorative parties, and activities to enable patients to socialize.

Psychological care is provided to patients and family members who present such a need and perhaps, for this reason, the psychological morbidity rates found in this study cannot be generalized for the entire population of HD patients. Even though fewer cases of depression and anxiety were found in comparison to reports in the literature, it is worth noting the importance of diagnosing and heeding psychological disorders in ESRD patients while considering the implications of such conditions on the quality of life and clinical responses of patients such as hospitalization and mortality (Zimmermann et al., 2004; Rosenthal-Asher et al., 2012).

In regard to social support, its impact on treatment adherence was only observed in regard to adherence to $\mathrm{HD}$, in which adherent patients presented higher scores of social support than those obtained by the non-adherent participants. Previous studies report association between social support and other aspects of treatment, such as diet, medication, and fluid restrictions (Cicolini, Palma, Simonetta \& Nicola, 2012; Untas, Rascle, Idier, Lasseur \& Combe, 2012; Ahari, Moshki \& Bahrami, 2014).

Incorporating analyses regarding the social support network available to patients into assessments and actions of the multidisciplinary staff is important because social support seems to be associated with improved clinical responses and quality of life for this population, as shown by Plantinga et al. (2010) and Rambod and Rafii (2010).

\section{Conclusions}

This study addressed associations between sociodemographic, clinical and psychological variables and treatment adherence among Brazilian patients undergoing HD. Limitations inherent to studies addressing treatment adherence should be taken into account, such as the fact that biological and behavioral measures are taken as indicators of adherence. One cannot be certain that a patient with satisfactory indicators does, in fact, adhere to treatment or that a patient with unsatisfactory indicators does not. There are numerous variables, some poorly understood, which make biological responses to the therapy to be individual responses. For this reason, the challenge to develop more efficacious techniques to assess treatment adherence remains and needs to be addressed in future studies. The study's small sample size and the fact that a convenience sample was adopted limit the generalization of results. It is worth noting that all the patients who met the inclusion criteria in the period of data collection were invited to participate in the study. Hence, increasing the number of participants would only be possible if other HD clinics outside the hospital had been included, which was not feasible.

Despite these limitations, the study's contribution lies on the evaluation of different aspects of hemodialysis and the possibility of analyzing adherence to treatment as a whole. Also, an objective parameter to assess adherence is proposed and can be used in other treatment centers to facilitate comparisons.

Association between adherence and depression, that is, depressive symptoms were more frequent among patients who correctly adhered to fluid restrictions, raise a new hypothesis: that restrictions imposed by the treatment lead to too many losses, which in turn lead to psychological disorders. This observation indicates the need of healthcare workers help patients to develop emotional and behavioral resources to overcome the restrictions imposed by the treatment, including new sources of satisfaction appropriate to their health conditions. Another possible reason for the fact that depressive symptoms were more frequent among patients who correctly adhere to fluid restrictions is that non-adherent patients are less aware of their illness and therefore less emotionally affected.

We must consider, however, that the low adherence to treatment has important clinical damage to the patient, which can lead to physical suffering in the medium or long term. Therefore, the emotional avoidance used by noncompliant patients should also be addressed by mental health workers because it may not work for a long period. 
Identifying the determinants and consequences of treatment adherence is important for the development of effective strategies intended to reduce the psychological impact of renal disease and hemodialysis, contributing to the wellbeing of this population.

\section{References}

Ahrari, S., Moshki, M., \& Bahrami, M. (2014). The relationship between social support and adherence of dietary and fluids restrictions among hemodialysis patients in Iran. Journal of Caring Sciences, 3(1), 11-19.

Alkatheri, A. M., Alyousif, S. M., Alshabanah, N., Albekairy, A. M., Alharbi, S., Alhejaili, F. F., et al. (2014). Medication adherence among adult patients on hemodialysis. Saudi Journal of Kidney Diseases and Transplantation, 25(4), 762-768.

Botega, N. J., Bio, M. R., Zomignani, M. A., Garcia Jr., C., \& Pereira, W. A. B. (1995). Transtornos do humor em enfermaria de clínica médica e validação de escala de medida (HAD) de ansiedade e depressão. Revista de Saúde Pública, 29(5), 355-363.

Carlos, P. R., Palha, P. F., Veiga, E. V., \& Beccaria, L. M. (2008). Perfil de hipertensos em um núcleo de saúde da família. Arquivos de Ciências da Saúde, 15(4), 176-181.

Cé, H. H., Kamile, Z. B., Ceza, M. R., \& Filla, S. (2008). Prevalência de transtornos depressivos em pacientes submetidos à hemodiálise em dois serviços de nefrologia na cidade de Criciúma. Arquivos Catarinenses de Medicina, 37(4), 12-15.

Cicolini, G., Palma, E., Simonetta, C., \& Di Nicola, M. (2012). Influence of family carers on haemodialyzed patients' adherence to dietary and fluid restrictions: an observational study. Journal of Advanced Nursing, 68(11), 2410-2417.

Clark, S., Farrington, K., \& Chilcot, J. (2014). Nonadherence in dialysis patients: prevalence, measurement, outcome, and psychological determinants. Seminars in Dialysis, 27(1), 42-49.

Cukor, D., Coplan, J., Brown, C., Friedman, S., Newville, H., Safier, M., et al. (2008). Anxiety disorders in adults treated by hemodialysis: a single-center study. American Journal of Kidney Diseases, 52(1), 128-136.

Dantas, L. G., Cruz, C., Rocha, M., Moura, J. A. Jr., Paschoalin, E., Paschoalin, S., et al. (2013). Prevalence and predictors of nonadherence to hemodialysis. Nephron Clinical Practice, 124(1-2), 67-71.

Durose, C. L., Holdsworth, M., Watson, V., \& Przygrodzka, F. (2004). Knowledge of dietary restrictions and the medical consequences of noncompliance by patients on hemodialysis are not predictive of dietary compliance. Journal of the American Dietetic Association, 104(1), 35-41.

Figueiredo, W. S., \& Schraiber, L. B. (2011). Concepções de gênero de homens usuários e profissionais de saúde de serviços de atenção primária e os possíveis impactos na saúde da população masculina, São Paulo, Brasil. Ciência \& Saúde Coletiva, 16(Supl.1), 935-944.

Griep, R. H., Chor, D., Faesrtein, E., \& Lopes, C. (2003). Apoio social: confiabilidade teste - reteste de escala no estudo pró-saúde. Caderno de Saúde Pública, 19(2), 625-634.

Griep, R. H., Chor, D., Faerstein, E., Werneck, G. L., \& Lopes, C. S. (2005). Validade de constructo de escala de apoio social do Medical Outcomes Study adaptada para o português no Estudo Pró-Saúde. Caderno de Saúde Pública, Rio de Janeiro, 21(3), 703-714.

Hartman, M., Dias-da-Costa, J. S., Olinto, M. T. A., Pattussi, M. P., \& Tramontini, A. (2007). Prevalência de hipertensão arterial sistêmica e fatores associados: um estudo de base populacional em mulheres no Sul do Brasil. Cadernos de Saúde Pública, 23(8), 1857-1866.

Ibrahim, S., Hossam, M., \& Belal, D. (2015). Study of non-compliance among chronica hemodialysis patients and its impacto on patients' outcomes. Saudi Journal of Kidney Diseases and Transplantation, 26(2), 243-249.

Khalil, A. A., \& Frazier, S. K. (2010). Depressive Symptoms and Dietary Nonadherence in Patients with End-Stage Renal Disease Receiving Hemodialysis: a review of quantitative evidence. Issues in Mental Health Nursing, 31(5), 324-330. 
Khalil, A. A., Frazier, S. K., Lennie, T. A., \& Sawaya, B. P. (2011). Depressive symptoms and dietary adherence in patients with end-stage renal disease. Journal of Renal Care, 37(1), 30-39.

Knauth, D. R., Couto, M. T., \& Figueiredo, W. S. (2012). A visão dos profissionais sobre a presença e as demandas dos homens nos serviços de saúde: perspectivas para a análise da implantação da Política Nacional de Atenção Integral à Saúde do Homem. Ciência \& Saúde Coletiva,17(10), 2617-2626.

Kugler, C., Vlaminck, H., Haverich, A., \& Maes, B. (2005). Nonadherence with diet and fluid restrictions among adults having hemodialysis. Journal of Nursing Scholarship, $1^{\text {st }}$ quarter, 25-29.

Madeiro, A. C., Machado, P. D. L. C., Bonfim, I. M., Braqueais, A. R., \& Lima, F. E. T. (2010). Adesão de portadores de insuficiência renal crônica ao tratamento de hemodiálise. Acta Paulista de Enfermagem, 23(4), 546-51.

Marcolino, J. A. M., Mathias, L. A. S. T., Piccinini, L., Guaratini, A. A., Suzuki, F. M., \& Alli, L. A. C. (2007). Escala Hospitalar de Ansiedade e Depressão: estudo da validade de critério e da confiabilidade com pacientes no pré-operatório. Revista Brasileira de Anestesiologia, 57(1), 52-62.

Martins, M. R. I., \& Cesarino, C. B. (2005). Qualidade de vida de pessoas com doença renal crônica em tratamento hemodialítico. Revista Latino-americana de Enfermagem, 13(5), 670-676.

Martins, M. T. S., Silva, L. F., Kraychete, A., Reis, D., Dias, L., Schnitman, G., et al. (2013). Potentially modifiable factors associated with non-adherence to phosphate binder use in patients on hemodialysis. BMC Nephrology, 14, 208.

Nabolsi, M. N., Wardam, L., \& Al-Halabi, J. O. (2015). Quality of life, depression, adherence to treatment and illness perception of patients oh haemodialysis. International Journal of Nursing Practice, 21(1), 1-10.

Nerbass, F. B., Morais, J. G., Dos Santos, R. G., Krüger, T. S., Koene, T. T., \& Da Luz Filho, H. A. (2010). Adesão e conhecimento sobre o tratamento da hiperfosfatemia de pacientes hiperfosfatêmicos em hemodiálise. Jornal Brasileiro de Nefrologia, 32(2), 149-155.

Nifa, S., \& Rudnicki, T. (2010). Depressão em pacientes renais crônicos em tratamento de hemodiálise. Revista da SBPH, 13(1), 64-75.

Ossareh, S., Tabrizian, S., Zebarjadi, M., \& Joodat, R.S. (2014). Prevalence of depression in maintenance hemodialysis patients and its correlation with adherence to medications. Iranian Journal of Kidney Disease, 8(6), 467-474.

Plantinga, L. C., Fink, N. E., Harrington-Levey, R., Finkelstein, F. O., Hebah, N., Powe, N. R., et al. (2010). Association of Social Support with Outcomes in Incident Dialysis Patients. Clinical Journal of The American Society of Nephrology, 5(8), 1480-1488.

Rambod, M., \& Rafii, F. (2010). Perceived Social Support and Quality of Life in Iranian Hemodialysis Patients. Journal of Nursing Scholarship, 42(3), 242-249.

Ribeiro, M. C. S. A., Barata, R. B., Almeida, M. F., \& Silva, Z. P. (2006). Perfil sociodemográfico e padrão de utilização de serviços de saúde para usuários e não-usuários do SUS - PNAD 2003. Ciência \& Saúde Coletiva, 11(4), 1011-1022.

Romãor, J. E. (2004). Doença Renal Crônica: definição, epidemiologia e classificação. Jornal Brasileiro de Nefrologia, 26(3), 1-3.

Rosenthal-Asher, D., Ver-Halen, N., \& Cukor, D. (2012). Depression and nonadherence predict mortality in hemodialysis treated end-stage renal disease patients. Hemodialysis International, 16(3), 387-393.

Schmid, H., Hartmann, B., \& Schiffl, H. (2009). Adherence to prescribed oral medication in adult patients undergoing chronic hemodialysis: A critical review of the literature. European Journal of Medical Research, 14(5), 185-190.

Sesso, R. C., Lopes, A. A., Thomé, F. S., Lugon, J. R., \& Dos Santos, D. R. (2011). Relatório do censo 
brasileiro de diálise de 2012. Jornal Brasileiro de Nefrologia, 33(4), 442-447.

Sgnaolin, V., Prado, A. E., \& Figueiredo, L. (2012). Adesão ao tratamento farmacológico de pacientes em hemodiálise. Jornal Brasileiro de Nefrologia, 34(2), 109-116.

Stamatakis, M. K., Pecora, P. G., \& Gunel, E. (1997). Factors influencing adherence in chronic dialysis patients with hyperphosphatemia. Journal of Renal Nutrition, 7(3), 144-148.

Thomas, L. K., Sargent, R. G., Michels, P. C., Richter, D. L., Valois, R. F., \& Moore, C. G. (2001). Identification of the factors associated with compliance to therapeutic diets in older adults with end stage renal disease. Journal of Renal Nutrition, 11(2), 80-89.

Turkmen, K., Erdur, F. M., Guney, I., Garipova, A., Turgut, F., Altintepe, L., et al. (2012). Sleep quality, depression, and quality of life in elderly hemodialysis patients. International Journal of Nephrology and Renovascular Disease, 5, 135-142.

Untas, A., Rascle, N., Idier, L., Lasseur, C., \& Combe, C. (2012). Family relations, mental health and adherence to nutritional guidelines in patients facing dialysis initiation. Psychology and Health, 27(7), 753-766.

Wileman, V., Chilcot, J., Norton, S., Hughes, L., Wellsted, D., \& Farrington, K. (2011). Choosing not to take phosphate binders: the role of dialysis patients' medication beliefs. Nephron Clinical Practice, 119(3), 205-213.

Zimmermann, P. R., Carvalho, J. O., \& Mari, J. J. (2004). Impacto da depressão e outros fatores psicossociais no prognóstico de pacientes renais crônicos. Revista de Psiquiatria - Rio Grande do Sul, 26(3), 312-318. 